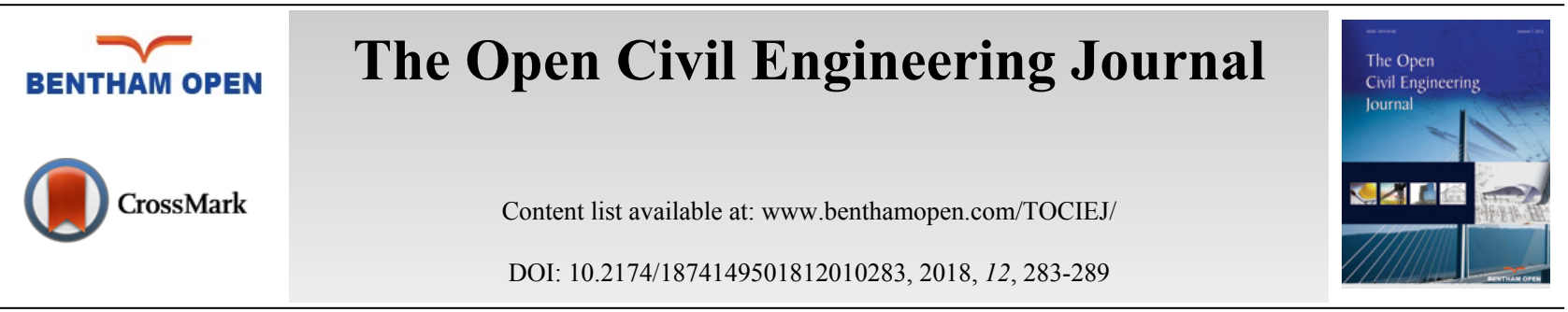

RESEARCH ARTICLE

\title{
Probabilistic Verification of Structural Stability Design Procedures
}

\author{
Zdeněk Kala* \\ Faculty of Civil Engineering, Brno University of Technology, Veveri $331 / 9560200$ Brno, Czech Republic
}

Received: June 21, 2018

Revised: August 27, 2018

Accepted: September 3, 2018

\begin{abstract}
:
Introduction:

This contribution presents a comparison of three methods of the statistical computation of the design load-carrying capacity of a steel plane frame. Two approaches of the European Standard Eurocode 3 and one stochastic approach are applied. The stochastic approach takes into account the random influence of all imperfections and can be applied to the reliability verification of design according to Eurocode 3.
\end{abstract}

\section{Methods:}

The columns and beams in the steel frame are modelled with beam elements using the stability solution with buckling length and the geometrically nonlinear solution. The stochastic computational model is based on the geometrically nonlinear solution and on the random influence of initial imperfections, whose random samplings are simulated using the Monte Carlo method.

\section{Results and Conclusion:}

The design load-carrying capacity of the steel plane frame computed using the stability solution with buckling length is in good agreement with the stochastic solution in which the design value is calculated as 0.1 percentile. On the contrary, the geometrically nonlinear solution according to Eurocode 3 gives the lowest (safest) values of design load-carrying capacity.

Keywords: Steel, Frame, Imperfections, Buckling, Sampling, Random, Reliability.

\section{INTRODUCTION}

The load-carrying capacity of frames with slender columns under compression is negatively influenced by stability phenomena, which must be taken into consideration during assessment and design [1]. Eurocode 3 [2] determines the load-carrying capacity in two basic ways. The first approach requires the calculation of the buckling length, nondimensional slenderness, and buckling coefficients. The second approach assumes the inclusion of initial imperfections, which reduce the load-carrying capacity, computed using a geometrically nonlinear solution with initial imperfections. Both of these approaches include simplifications, which in the case of the stability solution is the substitution of the influence of all imperfections with a buckling coefficient, or, in the case of the geometrically nonlinear solution with an initial geometrical imperfection. It is demonstrated in the presented paper that the design load-carrying capacity, which is computed using the concept of limit states of the Eurocode Standards [3, 4], may differ by up to 10\%. This brings up the question of what degree of risk could be accepted by a designer for the ultimate limit state, and how to determine the load-carrying capacity for economic and optimum reliable design with increased accuracy.

Initial imperfections are typically considered in advanced analyses [5, 6]. Conventional methods of modelling imperfections are based on the scaling of the eigen buckling modes [7, 8]. More advanced methods consider separately the system (out-of-plumb) and the bow (out of straightness) imperfections and thereby model more

\footnotetext{
* Address correspondence to this author at the Faculty of Civil Engineering, Brno University of Technology, Veveri 331/95 602 00 Brno, Czech Republic, Tel: +420 541147382; E-mail: kala.z@fce.vutbr.cz
} 
accurately the shapes and magnitudes of initial curvatures obtained from the results of experimental research, see for $e . g$ [9]. Probabilistic analysis of reliability requires the inclusion of all imperfections as random variables [10] or random fields [11]. Input imperfections with high global sensitivity to the limit states can be identified as the key variables using modern methods of sensitivity analysis [12]. The failure-probability-based sensitivity, which measures the effect of input variables on the structural failure probability, can provide useful information on reliability-based design optimization [13]. In cases where a satisfactory number of statistically applicable data is available, one of the possibilities for determining the design load-carrying capacity is by using stochastic analysis and design reliability conditions according to the European Standard EN 1990 [14].

The standard and stochastic analyses of reliability presented in this article are computed using the algorithm and software developed by the author of this paper $[15,16]$. The paper links up with preceding experimental research $[17$, $18]$, research in the field of reliability theory [19 - 22], and decision-making methods in application to civil engineering $[23,24]$.

\section{DESIGN LOAD-CARRYING CAPACITY}

The subject of study is the steel plane frame illustrated in Fig. (1). The left column is stressed by compressive force $F$. The right column is stressed by compressive force $\delta \mathrm{F}$ with parameter. The meshing of the frame geometry was carried out using beam elements, where the elastic stiffness matrix and the geometric stiffness matrix were published in [8]. Each column was meshed with eighteen beam finite elements. The beam finite element, including the stiffness matrix and two geometric matrices, was published in detail in [15]. The cross beam was meshed with eight beam finite elements. It can be noted that this beam finite element has been effectively used in a number of studies [15, 16, 20, 25 27]. Steel of grade S235 was used for the numerical study performed in this article.

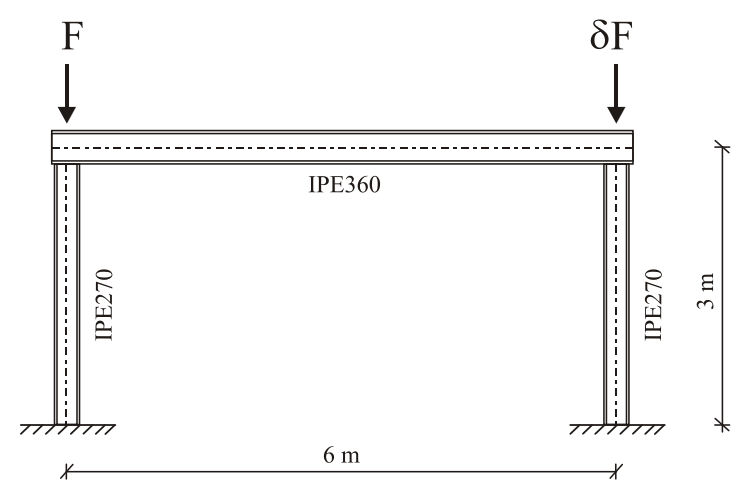

Fig. (1). Steel plane frame with columns under compression.

\subsection{Stability Solution with Buckling Length}

The stability solution with buckling length is based on the calculation of the critical load action $F_{c r}$ at which the system (without imperfections) loses its stability (Table 1). Axial forces in beams intended for buckling with a displacement of joints and their respective buckling lengths correspond to the critical load action.

Table 1. The buckling length of columns 1 and 2.

\begin{tabular}{|c|c|c|c|}
\hline$\delta$ & 1 & 0.5 & 0 \\
\hline$L_{c r 1}[\mathrm{~m}]$ & 6.7111 & 5.8181 & 4.79023 \\
\hline$L_{c r 2}[\mathrm{~m}]$ & 6.7111 & 8.2281 & $\infty$ \\
\hline$F_{\max }[\mathrm{kN}]$ & 945.3 & 979.6 & 1012.5 \\
\hline
\end{tabular}

The design load-carrying capacity $F_{\max }$ can be determined for steel S235 according to Eurocode 3 [2]. The standard provides the calculation method of the buckling coefficient using buckling lengths $L_{c r l}$ and $L_{c r 2}$. Eurocode 3 [2] further gives procedures for the computation of the design load-carrying capacity and for the assessment of the steel plane frame at the ultimate limit state. Nevertheless, it permits simplifications, which lead to larger or smaller inaccuracies in the dimensioning of beams. It is a paradox of buckling lengths that extremely high buckling lengths are obtained for columns with small axial force (see $L_{c r 2}=\infty$ of the right column for $\delta=0$ ). 


\subsection{The Geometrically Nonlinear Solution}

Eurocode 3 [2] makes it possible to compute the design load-carrying capacity with the use of the geometrically nonlinear solution with consideration to the influence of all imperfections. The imperfections include system imperfections (out-of-plumb) and bow (out-of-straightness) imperfections of the columns under compression (Fig. 2).
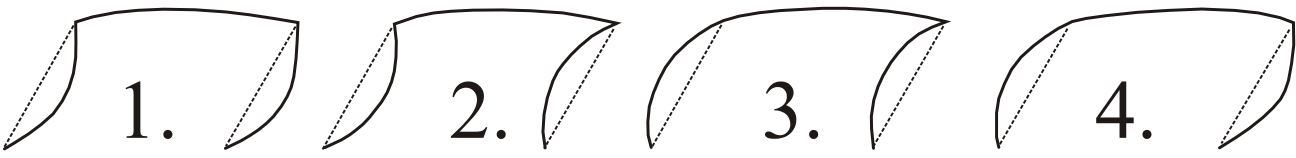

\begin{tabular}{|c|c|}
\hline$\delta$ & $F_{\max }$ \\
\hline 1,0 & $874 \mathrm{kN}$ \\
\hline 0,5 & $944 \mathrm{kN}$ \\
\hline 0,0 & $1000 \mathrm{kN}$ \\
\hline
\end{tabular}

\begin{tabular}{|c|c|}
\hline$\delta$ & $F_{\max }$ \\
\hline 1,0 & $871 \mathrm{kN}$ \\
\hline 0,5 & $951 \mathrm{kN}$ \\
\hline 0,0 & $1000 \mathrm{kN}$ \\
\hline
\end{tabular}

\begin{tabular}{|c|c|}
\hline$\delta$ & $F_{\max }$ \\
\hline 1,0 & $883 \mathrm{kN}$ \\
\hline 0,5 & $945 \mathrm{kN}$ \\
\hline 0,0 & $995 \mathrm{kN}$ \\
\hline
\end{tabular}

\begin{tabular}{|c|c|}
\hline$\delta$ & $F_{\max }$ \\
\hline 1,0 & $8805 \mathrm{kN}$ \\
\hline 0,5 & $940 \mathrm{kN}$ \\
\hline 0,0 & $995 \mathrm{kN}$ \\
\hline
\end{tabular}
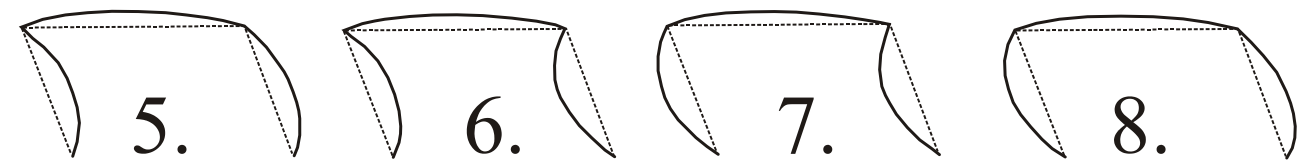

\begin{tabular}{|c|c|}
\hline$\delta$ & $F_{\max }$ \\
\hline 1,0 & $883 \mathrm{kN}$ \\
\hline 0,5 & $928 \mathrm{kN}$ \\
\hline 0,0 & $974 \mathrm{kN}$ \\
\hline
\end{tabular}

\begin{tabular}{|c|c|}
\hline$\delta$ & $F_{\max }$ \\
\hline 1,0 & $871 \mathrm{kN}$ \\
\hline 0,5 & $920 \mathrm{kN}$ \\
\hline 0,0 & $974 \mathrm{kN}$ \\
\hline
\end{tabular}

\begin{tabular}{|c|c|}
\hline$\delta$ & $F_{\max }$ \\
\hline 1,0 & $874 \mathrm{kN}$ \\
\hline 0,5 & $925 \mathrm{kN}$ \\
\hline 0,0 & $980 \mathrm{kN}$ \\
\hline
\end{tabular}

\begin{tabular}{|c|c|}
\hline$\delta$ & $F_{\max }$ \\
\hline 1,0 & $880 \mathrm{kN}$ \\
\hline 0,5 & $933 \mathrm{kN}$ \\
\hline 0,0 & $980 \mathrm{kN}$ \\
\hline
\end{tabular}

Fig. (2). The combination of imperfections.

The load-carrying capacity was determined using the Euler method in combination with the Newton-Raphson method. The bow imperfection was introduced in the shape of a half-wave of the sine function with a so-called equivalent amplitude $e=9.33 \mathrm{~mm}$ [2]. The out-of-plumb imperfections were introduced as 1:200 of the height of the frame $[2,25]$. The out-of-plumb or out-of-vertical imperfections can be applied in all horizontal directions but were considered in only one direction [2]. The frame can be solved using eight imperfections of frames (Fig. 2). Eight variants of imperfections yield different values of the design load-carrying capacity, the maximum and minimum values being interesting (Table 2).

Table 2. The design load-carrying capacity.

\begin{tabular}{|c|c|c|c|}
\hline$\delta$ & 1 & 0.5 & 0 \\
\hline Minimum $F_{\max }[\mathrm{kN}]$ & 870.6 & 920 & 974.1 \\
\hline Maximum $F_{\max }[\mathrm{kN}]$ & 883.2 & 951.1 & 1000 \\
\hline difference $[\%]$ & 1.4 & 3.4 & 2.7 \\
\hline
\end{tabular}

For more complicated systems with more beams, it is not possible to study all combinations of bow and out-ofplumb imperfections, and differences between the minimum and maximum load-carrying capacities can be more significant.

\subsection{The Stochastic Analysis According to Standard EN1990}

According to EN1990 [14], one of the possibilities for determining the design load-carrying capacity is the application of the statistical solution with consideration to the random influence of all imperfections. Stochastic models of the geometrical imperfections of the frame in Fig. (1) were published in [26, 27]. It was assumed that the initial bow curvature of the column in the shape of a one-half wave of the sine function with $e$ would have a Gauss probability density function with zero mean value and standard deviation $S_{e 0}=1.5 \mathrm{~mm}$. This probabilistic model is based on the rule $2 S_{x}$, i.e, that $95 \%$ random realizations lie within the interval $\pm L / 1000=0.003 \mathrm{~m}$. Out-of-plumb imperfections of the columns are introduced with Gauss pdf with zero mean value; the standard deviation was introduced using the method 
described in [27]. The principle of forming stochastic combinations (random realizations) of initial imperfections is explained in detail in [27] (Fig. 3).
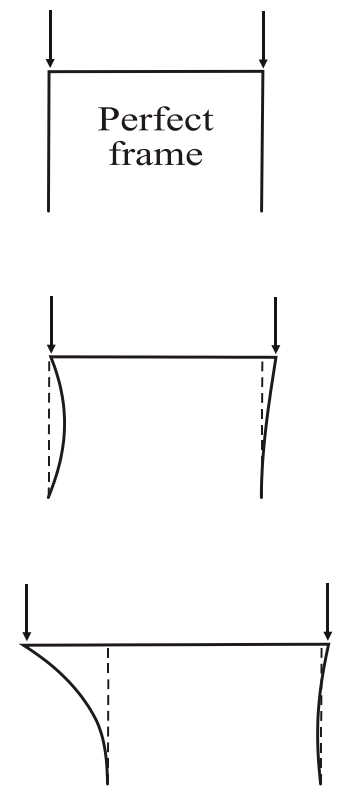
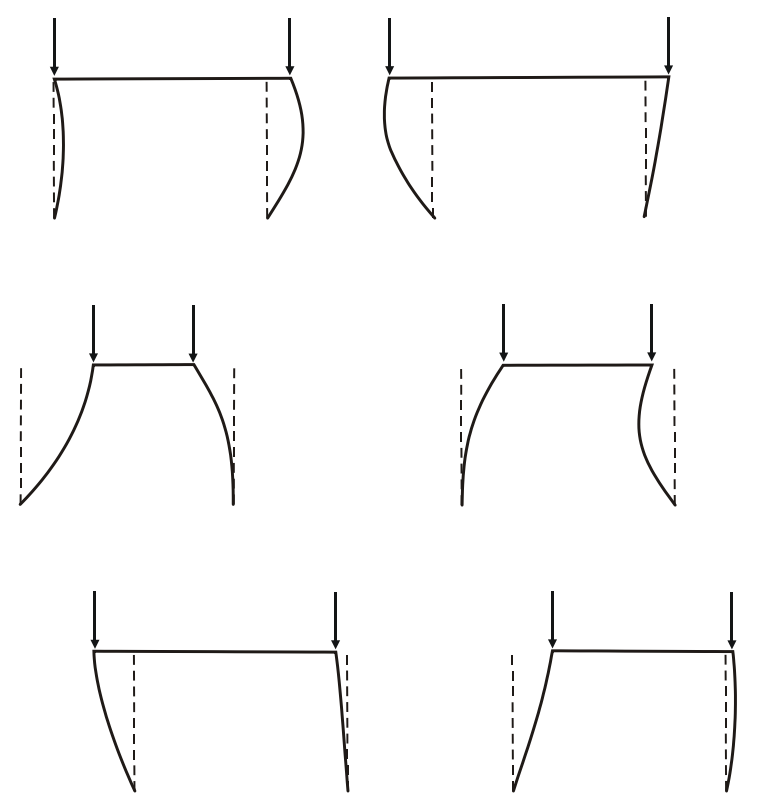

Fig. (3). The random realizations of initial imperfections [27].

The statistical characteristics of imperfections of cross-sectional dimensions were introduced according to the results of experimental research $[17,18]$. The yield strength of steel grade S235 was introduced as a random variable with normal probability distribution with mean value $m_{f y}=297.3 \mathrm{MPa}$ and standard deviation $S_{f y}=16.8 \mathrm{MPa}$ [17]. The residual stress was not considered. An ideally elastic-plastic material without hardening was considered. The influence of deviations of physical-mechanical characteristics was taken into account by the variability of Young's modulus $E$, the mean value was considered as $m_{E}=210 \mathrm{GPa}$ and standard deviation $S_{E}=10.5 \mathrm{GPa}$ [28]. The residual stress was not considered.

The geometrically and materially nonlinear solution was chosen for the computational model [17]. Statistical analysis was performed for two hundred thousand runs of the Monte Carlo method. $F$ due to which the yield strength is reached in the most stressed point of the web of the left or the right column was calculated in each run of the Monte Carlo method. The random variability of the load-carrying capacity is due to the random variability of initial imperfections. For design reliability index $\beta_{d}=3.8$, the design load-carrying capacity can be computed as 0.1 percentile [14]. Reliability index $\beta$ has a target value of 3.8 provided that we consider the ultimate limit state for common design situations within the reference period of 50 years [29]. The design reliability index $\beta_{d}=3.8$ can be used for medium consequences of loss of human life, economic, social or environmental consequences. The one hundredth lowest loadcarrying capacity from the statistical set of sampling (runs) of load-carrying capacities sorted in ascending order can be considered as the estimate of the design value. The design load-carrying capacity computed as 0.1 percentile [14] is an alternative to the approaches of the standard [2].

Table 3. 0.1 percentile of the load-carrying capacity.

\begin{tabular}{|c|c|c|c|}
\hline$\delta$ & 1 & 0.5 & 0 \\
\hline 0.1 percentile $[\mathrm{kN}]$ & 949.9 & 984.4 & 1016.6 \\
\hline
\end{tabular}

A graphical summarization of the design values of the load-carrying capacity is shown in Fig. (4) and Table 3 . It is evident that the safest design having the lowest load-carrying capacity is reached using the geometrically nonlinear solution given in Chapter 2.2. This design also contains certain subjective uncertainty, which is introduced by the engineer when choosing the shape of the imperfection from Fig. (2). Selection of the shape of the imperfection gives a certain freedom in design in which the engineer may reflect the effort for the lightest structure (economic aspect) or the effort for a robust structure (safety aspect). In the case of complex steel structures with an equivalent number of 
columns and beams, the differences between the load carrying capacities due to the subjective selection of the shape of the imperfection may be even more significant, thus, design using the geometrically nonlinear solution must be approached with the utmost caution and responsibility.

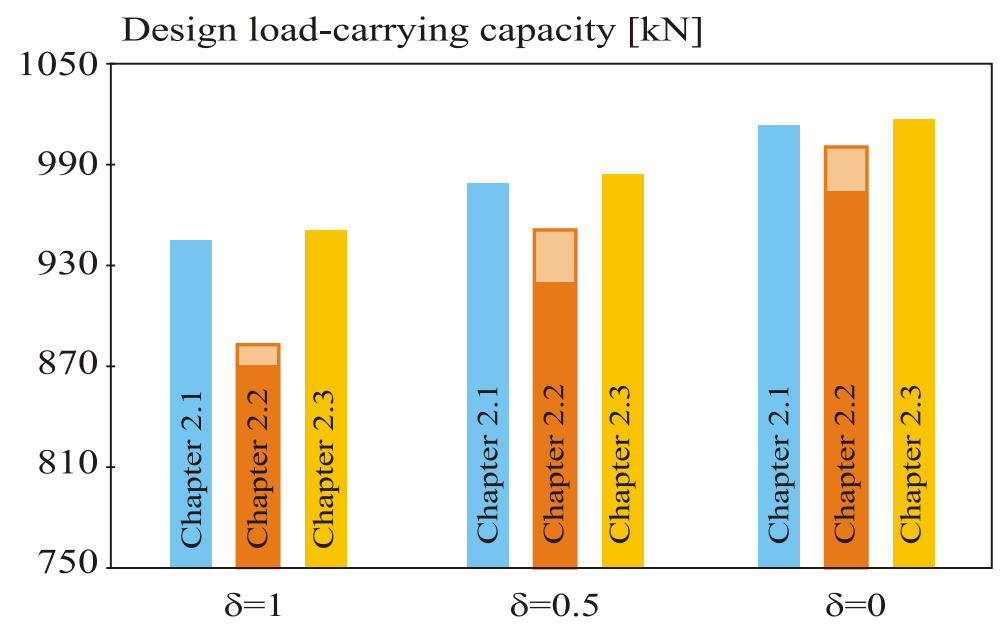

Fig. (4). Comparison of three approaches of the computation of load-carrying capacity.

The stochastic solution leads to approximately similar results as the stability solution with buckling length Fig. (4). The stability solution with buckling length is well established in engineering practice and in the case of the presented analysis is shown to be in good agreement with the design reliability conditions of the Standard EN1990 [14]. In the stochastic solution, refinement of the shape of the initial curvature of the column can be discussed, for $e . g$. using random fields [11]. Modelling using random fields can refine the load-carrying capacity if the non-dimensional slenderness of the columns is close to one. However, knowledge of the correlation length is necessary. Moreover, greater influence can be expected from the out-of-plumb imperfections [27]. One way to evaluate the influence of initial imperfections is to apply sensitivity analysis methods [30, 31].

\section{CONCLUSION}

The safety and reliability of structural design according to Eurocode 3 [2] based on the concept of limit states require optimally set values of the partial safety factors. Design according to the Eurocode Standards is a compromise between economy and reliability of supporting structures and should be satisfactory for the majority of common design situations. Nevertheless, higher or lower safety and reliability can be required in some cases, which may be achieved using a design based on the stochastic calculation of design values. The paper discusses the stochastic computation of the design load-carrying capacity as 0.1 percentile for design reliability index of medium (standard) value $\beta_{d}=3.8$. This reliability was applied to verify the design reliability of the load-carrying capacity calculated according to EC3 [2]. It was found that the design load-carrying capacity calculated as 0.1 percentile is in relatively good agreement with the design load-carrying capacity obtained using the stability solution with buckling load. The lowest design load-carrying capacity (the highest design reliability) was obtained using the geometrically nonlinear solution with initial imperfections. The conclusions reached are formulated on the basis of the results of one example of a steel plane frame and additional reliability analyses are necessary for the formulation of more general conclusions. From a long-term point of view, it is necessary to strive for the continuous study of material and geometrical characteristics of steel products by experimental research, because they provide important inputs for reliability analysis.

\section{CONSENT FOR PUBLICATION}

Not applicable.

\section{CONFLICT OF INTEREST}

The author declares no conflict of interest, financial or otherwise. 


\section{ACKNOWLEDGEMENTS}

The article was elaborated within the framework of project GAČR 18-13212S.

\section{REFERENCES}

[1] T.V. Galambos, T.V. galambos, guide to stability design criteria for metal structures., 5th ed Wiley: New York, 1998.

[2] EN 1993-1-1, (2005)., Eurocode 3: Design of steel structures - part 1-1: General rules and rules for buildings. , European Committee for Standardization: Brussels (Belgium), 1998.

[3] G. Sedlacek, and H. Stangenberg, "Design philosophy of eurocodes — background information", J. Construct. Steel Res., vol. 54, no. 1, pp. 173-190, 2000. [http://dx.doi.org/10.1016/S0143-974X(99)00096-6]

[4] G. Sedlacek, and C. Müller, "The European standard family and its basis", J. Construct. Steel Res., vol. 62, no. 11, pp. 1047-1059, 2006. [http://dx.doi.org/10.1016/j.jcsr.2006.06.027]

[5] I. Kalogeris, and V. Papadopoulos, "Limit analysis of stochastic structures in the framework of the probability density evolution method", Eng. Struct., vol. 160, pp. 304-3013, 2018. [http://dx.doi.org/10.1016/j.engstruct.2018.01.020]

[6] J. Lellep, and T. Kraav, "Buckling of beams and columns with defects", Int. J. Struct. Stab. Dyn., vol. 16, no. 8, 2016. [http://dx.doi.org/10.1142/S0219455415500480]

[7] E. Chladný, and M. Štujberová, "Frames with unique global and local imperfection in the shape of the elastic buckling mode (Part 1)", Stahlbau, vol. 82, no. 8, pp. 609-617, 2013. [http://dx.doi.org/10.1002/stab.201310080]

[8] J. Brodniansky, "Equivalent unique global and local initial imperfection - imperfection in en 1993-1-1 and en 1999-1-1 clause 5.3.2 (11) calculation procedure and discovered obstacles", Pollack Periodica, vol. 12, no. 3, pp. 33-42, 2017. [http://dx.doi.org/10.1556/606.2017.12.3.4]

[9] C. Liu, L. He, Z. Wu, and J. Yuan, "Experimental study on joint stiffness with vision-based system and geometric imperfections of temporary member structure", J. Civ. Eng. Manag., vol. 24, no. 1, pp. 43-52, 2018. [http://dx.doi.org/10.3846/jcem.2018.299]

[10] D. De Domenico, G. Falsone, and D. Settineri, "Probabilistic buckling analysis of beam-column elements with geometric imperfections and various boundary conditions", Meccanica, vol. 53, no. 4-5, pp. 1001-1013, 2018. [http://dx.doi.org/10.1007/s11012-017-0763-5]

[11] Z. Kala, J. Valeš, and J. Jönsson, "Random fields of initial out of straightness leading to column buckling", J. Civ. Eng. Manag., vol. 23, no. 7, pp. 902-913, 2017. [http://dx.doi.org/10.3846/13923730.2017.1341957]

[12] W. Liu, X. Wu, L. Zhang, Y. Wang, and J. Teng, "Sensitivity analysis of structural health risk in operational tunnels", Autom. Construct., vol. 94, pp. 135-153, 2018. [http://dx.doi.org/10.1016/j.autcon.2018.06.008]

[13] Y. Wang, S. Xiao, and Z. Lu, "An efficient method based on bayes' theorem to estimate the failure-probability-based sensitivity measure", Mech. Syst. Signal Process., vol. 115, pp. 607-620, 2019.

[http://dx.doi.org/10.1016/j.ymssp.2018.06.017]

[14] EN 1990, Eurocode: Basis of structural design, CEN - european committee for standardization. European committee for standardization, Brussels, Belgium, 2002.

[15] Z. Kala, "Geometrically non-linear finite element reliability analysis of steel plane frames with initial imperfections", J. Civ. Eng. Manag., vol. 18 , no. 1, pp. 81-90, 2012. [http://dx.doi.org/10.3846/13923730.2012.655306]

[16] Z. Kala, "Computation of equilibrium paths in nonlinear finite element models", In: $20^{\text {th }}$ International Conference on Circuits, Systems, Communications and Computers, vol. 76, 2016. [http://dx.doi.org/10.1051/matecconf/20167604026]

[17] J. Melcher, Z. Kala, M. Holický, M. Fajkus, and L. Rozlívka, "Design characteristics of structural steels based on statistical analysis of metallurgical products", J. Construct. Steel Res., vol. 60, no. 3-5, pp. 795-808, 2004. [http://dx.doi.org/10.1016/S0143-974X(03)00144-5]

[18] Z. Kala, J. Melcher, and L. Puklický, "Material and geometrical characteristics of structural steels sased on statistical analysis of metallurgical products", J. Civ. Eng. Manag., vol. 15, no. 3, pp. 299-307, 2009. [http://dx.doi.org/10.3846/1392-3730.2009.15.299-307]

[19] Z. Kala, and J. Kala, "Sensitivity analysis of stability problems of steel structures using shell finite elements and nonlinear computation methods", In: WSEAS transactions on applied and theoretical Mechanics, vol. 4. 2009, no. 3, pp. 105-114.

[20] Z. Kala, "Sensitivity analysis of carrying capacity of steel plane frames to imperfections", In: AIP Conference Proceedings, vol. 1048. 2008, pp. 298-301. 
[http://dx.doi.org/10.1063/1.2990917]

[21] Z. Kala, "Reliability of steel members designed in accordance with the code design concepts", In: AIP Conference Proceedings, vol. 1281. 2010, pp. 579-582.

[http://dx.doi.org/10.1063/1.3498542]

[22] Z. Kala, "Influence of partial safety factors on design reliability of steel structures - probability and fuzzy probability assessments", J. Civ. Eng. Manag., vol. 13, no. 4, pp. 291-296, 2007. [http://dx.doi.org/10.1080/13923730.2007.9636449]

[23] J. Antucheviciene, Z. Kala, M. Marzouk, and E.R. Vaidogas, "Decision making methods and applications in civil engineering", Math. Probl. Eng., vol. 2015, no. 160569, 2015. [http://dx.doi.org/10.1155/2015/160569]

[24] J. Antucheviciene, Z. Kala, M. Marzouk, and E.R. Vaidogas, "Solving civil engineering problems by means of fuzzy and stochastic MCDM methods: Current state and future research", Math. Probl. Eng., vol. 2015, no. 362579, 2015. [http://dx.doi.org/10.1155/2015/362579]

[25] Z. Kala, "Global sensitivity analysis in stability problems of steel frame structures", J. Civ. Eng. Manag., vol. 22, no. 3, pp. 417-424, 2016. [http://dx.doi.org/10.3846/13923730.2015.1073618]

[26] Z. Kala, "Sensitivity analysis of stability problems of steel plane frames", Thin-walled Struct., vol. 49, no. 5, pp. 645-651, 2011. [http://dx.doi.org/10.1016/j.tws.2010.09.006]

[27] Z. Kala, "Sensitivity analysis of steel plane frames with initial imperfections", Eng. Struct., vol. 33, no. 8, pp. 2342-2349, 2011. [http://dx.doi.org/10.1016/j.engstruct.2011.04.007]

[28] G.C. Soares, "Uncertainty modelling in plate buckling", Struct. Saf., vol. 5, no. 1, pp. 17-34, 1988. [http://dx.doi.org/10.1016/0167-4730(88)90003-3]

[29] Z. Kala, "Reliability analysis of the lateral torsional buckling resistance and the ultimate limit state of steel beams with random imperfections", J. Civ. Eng. Manag., vol. 21, no. 7, pp. 902-911, 2015. [http://dx.doi.org/10.3846/13923730.2014.971130]

[30] Z. Kala, "Sensitivity analysis in advanced building industry", Procedia Soc. Behav. Sci., vol. 2, no. 6, pp. 7682-7683, 2010. [http://dx.doi.org/10.1016/j.sbspro.2010.05.177]

[31] Z. Kala, "Global sensitivity analysis of lateral-torsional buckling resistance based on finite element simulations", Eng. Struct., vol. 134, pp. 37-47, 2017.

[http://dx.doi.org/10.1016/j.engstruct.2016.12.032]

\section{(C) 2018 Zdeněk Kala.}

This is an open access article distributed under the terms of the Creative Commons Attribution 4.0 International Public License (CC-BY 4.0), a copy of which is available at: (https://creativecommons.org/licenses/by/4.0/legalcode). This license permits unrestricted use, distribution, and reproduction in any medium, provided the original author and source are credited. 